\title{
Size of Primary Thyroid Tumor is Not a Predictor for Lymph Node Affection in Early Subsequent Recurrence in WDTC
}

\author{
HOSSAM M. FAREED, M.Sc.*; HAITHAM FEKRY, M.D.*; TAREK EL-BARADIE, M.D.*; \\ MAGDY KOTB, M.D.***; INAS EL-ATAR, M.D.** and ISMAEEL A. MORAD, M.D.* \\ The Departments of Surgery*, Biostatistics** and Nuclear Medicine ${ }^{* * *}$, The National Cancer Institute, Cairo
}

\begin{abstract}
Background: Several factors were found to affect recurrence and prognosis in patients with Well Differentiated Thyroid Cancer (WDTC). Although greater tumor size ( $>4 \mathrm{~cm}$.) was found to be a predictor for multiple recurrence in patients with WDTC, it didn't appear to predict for mortality in those patients. In our study size of the primary tumor in thyroid gland when first removed didn't appear to affect L.N. metastasis in subsequent early recurrence (less than 12 months).
\end{abstract}

Aim of Study: To assess the effect of size of primary thyroid tumor on lymph node affection by tumor in early recurrence in patients with recurrent well differentiated thyroid cancer.

Patients and Methods: Forty patients with recurrent WDTC were studied between June 2014 and June 2015, where data was collected regarding primary tumor characteristics, demographic data for all patients, and type of surgery done. Adequate management and surgery were done for all patients, and L.N.s status was assessed pathologically. Data was taken and statistically analyzed.

Results: Thirty five patients presented with nodal affection in first recurrence with primary thyroid tumor size ranged between 1 and $8 \mathrm{~cm}$ with median size $6 \mathrm{~cm}$. In the 5 patients with no L.N. affection in first recurrence thyroid tumor size ranged between 5 and $8 \mathrm{~cm}$. with median size reaching $6 \mathrm{~cm}$. In our study, size of primary tumor in thyroid gland when first removed showed that it had no effect on L.N. metastasis in subsequent first recurrence.

Conclusions: Although size of primary thyroid tumor when first removed is an important factor that may affect recurrence and hence patients outcome, however it didn't show that it may affect L.N.s metastasis in subsequent recurrence. Size of primary thyroid tumor is not a predictor for L.N. metastasis in subsequent first recurrence.

Key Words: Size - Thyroid - Tumor - Lymph nodes - Recurrence.

Correspondence to: Dr. Hossam M. Fareed, The Department of Surgery, The National Cancer Institute, Cairo

\section{Introduction}

SEVERAL factors may affect recurrence and prognosis in patients with Well Differentiated Thyroid Cancer (WDTC). Extent of disease at initial diagnosis was found to strongly influences prognosis in patients with WDTC. Large size of the tumor, especially $>4 \mathrm{~cm}$, has been shown to adversely affect mortality in several trials [1-4] Although greater tumor size $(>4 \mathrm{~cm})$ was found to be a predictor of multiple recurrences in patient with WDTC, it did not appear to predict for mortality in this population [5]

The AJCC staging system, which incorporate the TNM (tumor, lymph nodes, metastasis) classification, is the current standard in staging thyroid malignancies. Stage III, IV disease (III=extra thyroidal extension, or nodal metastasis, $\mathrm{IV}=$ distant metastasis) appeared to have an increase risk of mortality among patients with multiple recurrences of WDTC [6]. This was in agreement with other authors, who had found that advanced stage disease not only increase the risk of recurrence, but also significantly reduce disease specific survival [7-11] .

Theresa H. et al., showed that neither lymphatic invasion, nor initial neck dissection showed a statistical significance for mortality among patients with WDTC. However, the presence of vascular invasion did appear to have poor prognosis $[2,3,6]$.

\section{Patients and Methods}

The study was carried on 40 consecutive patients with neck recurrence of well differentiated thyroid cancer who were referred to National Cancer Institute between June 2014 and June 2015. Thirty five of them had associated nodal recurrence that had developed after management of their 
primary disease. 20 patients had Radioactive Iodine (RAI) as part of their management plan while the other 15 didn't receive (RAI).

For all patient with recurrent disease, data was recorded on demographics, investigation done, initial stage of the disease, size of primary tumor in thyroid gland when first removed, number and location of recurrence, time till recurrence, type of surgery done, and treatment received. Data was statistically, analyzed, and tabled.

Patients with recurrent disease were identified by evidence of disease in imaging study, elevated thyroglobulin level post-operatively or during follow-up.

Surgery was done for recurrent disease as indicated. Study included patients who had done hemithyroidectomy and had other lobe, operative bed or nodal recurrence, patients who had done total thyroidectomy and had operative bed or nodal recurrence, and patients who had done thyroidectomy with neck dissection and had nodal or operative bed recurrence. Follow-up of these patients was taken by history and physical examination, laboratory tests (thyroglobin level) and neck imaging (U.S, C.T, MRI). Patients with incomplete or missing data were excluded from the study.

Histopathology and risk factors were documented. Patterns of recurrence and associated risk factors for each type of recurrence, (age, sex, most common site of recurrence, level of L.N. affection, number of recurrence, recurrence in less than 12 months) were identified. Surgical management of recurrent thyroid cancer patients was described regarding type of surgery, extent of resection, and recurrence in less than 12 months. Data was statistically analyzed and tabled.

All patient meeting selective criteria of the study were included in a one year starting from $12 / 2014$ to $12 / 2015$. Last patient will be followedup for 12 months.

Data was managed using SPSS Version 20.0 (IL., Chicago). Data was described as mean and standard deviation. (Or median and range as appropriate). Categorical data was expressed as numbers and percentage. Numbers and percentage among groups were compared using Chi-square/ Fisher exact tests.

Means we're compared by $t$-test or ANOVA (parametric or non-parametric as appropriate. Survival was estimated by Kaplan Meier survival analysis, and log rank test. $p$-value is set significant at 0.05 level.

\section{Results}

Forty patients underwent surgery for recurrent Differentiated Thyroid Cancer (DTC), with female constituting 29 patients (72.5\%)and male 11 patients $(27.5 \%)$ with male to female ratio (1: 2.63).

Average males age was (45.09y) and average female age was $(45.44 \mathrm{y})$, with youngest male age was (14y), and oldest (61y), and youngest in female was (22y) and oldest (67y), with overall $(37.5 \%)$ below or equal (40y), and (62,5\%) above (40y).

Thirty one patients had unilobar tumors (77.5\%), and nine patients had bilobar tumors $(22.5 \%)$. Six patients presented with infiltration of their primary tumors of surrounding soft tissues (15\%), five patients infiltrating strap muscle $(12.5 \%)$, and one patient with infiltration of trachea and pharynx $(2.5 \%)$. (With classic papillary pathology).

From the forty patients in the study, thirty four patients came with history of previous total thyroidectomy $(85 \%)$, and six patients came with history of previous hemi thyroidectomy (15\%).

The size of the primary tumor in the thyroid gland when first removed was known in thirty eight patients, with mean size (4) $\mathrm{cm}$, median size was (3.5)cm with Standard Deviation (SD) (1.9), with least size was (1) $\mathrm{cm}$, and largest size was (8) $\mathrm{cm}$.

Lymph nodes affection in 1 st recurrence was present in thirty five patients $(87.5 \%)$, only one of them had level VI alone affection (2.5\%). (With papillary classic pathology).

Size of thyroid tumors in those 35 patients ranged between $1 \mathrm{~cm}$. and $8 \mathrm{~cm}$. with median size $3 \mathrm{~cm}_{1}$ In the five patients without L.N. affection in the ${ }^{1 \mathrm{st}}$ recurrence, size of thyroid tumors ranged between 5 and $8 \mathrm{~cm}$. with median size $6 \mathrm{~cm}$.

In the five patients without L.N. affection, one patient had follicular insular pathology, and the other four with papillary classic pathology. In the other 35 patients with L.N. affection, 24 patients presented with papillary classic pathology, 4 with follicular insular pathology, 3 with papillary follicular variant, and one patient with each of the following pathology: Papillary tall cell, papillary columnar, papillary oncocytic, and follicular hurtle cell pathology.

In patients with out L.N. recurrence, time till recurrence ranged between 3 and 40 months, while 
patients with L.N. affection time till recurrence ranged between 2 and 130 months.

Bilateral L.N. affection was found in 8 of the thirty five patients with L.N affection (22.8\%) and bilateral central L.N affection in 3 patients $(8.5 \%)$ after exclusion of one patient without accurate data.

Of the 8 patients with bilateral L.N. affection, 6 patients had papillary classic pathology $(75 \%)$, one patient papillary follicular variant $(12.5 \%)$, and one patient with follicular insular pathology $(12.5 \%)$.

Of the 8 patients with bilateral L.N. affection, 7 patients had unilateral lesions in the thyroid gland when first removed (87.5\%), and one patient had bilateral thyroid lesions $(12.5 \%)$ [patient was with papillary classic pathology].

Thyroid lesions size in those patients ranged between 3 and $5 \mathrm{~cm}$. Five patients were female $(62.5 \%)$. Four patients were in the third decade (50\%), one patient in the fourth decade $(12.5 \%)$, and one in the seven decade (12.5\%). Time till recurrence was 48 months in the male patient, and ranged between 7 and 17 months in female.

In patients with unilateral L.N affection, eight patients had bilateral thyroid lesion in primary surgery when thyroid first removed $(28.5 \%)$ with tumor size ranged between 0.5 and $3 \mathrm{~cm}$.

Size of the tumors in thyroid gland when first removed was identified in patients of with second recurrence. Patients had tumors ranged between $1 \mathrm{~cm}$ and $7 \mathrm{~cm}$. Of note all patients with second recurrence had L.N. affection.

\section{Discussion}

Many factors can affect thyroid cancer recurrence, but final conclusions have not been reached. The results of some studies show that the pathological type, staging, degree of extrathyroid invasion, lymph node metastasis, age, and initial surgery approach are related to thyroid cancer recurrence $[12,13]$

The AJCC staging system, which incorporates the TNM (tumor, lymph nodes, and metastases) classification, is the current standard in staging thyroid malignancies. Stage III/IV disease (III= ETS or nodal metastases, IV=distant metastases) appears to portend an increased risk of mortality among patients with multiple recurrences of WDTC $[11,14,15]$
This is in agreement with other authors, who have found that advanced stage disease not only increases the risk of recurrence but also significantly reduces disease-specific survival $[\mathbf{1 , 5 , 1 0}$, $11,14,15]$.

Extent of disease at initial diagnosis strongly influences prognosis in patients with WDTC. Large tumor size, especially $>4 \mathrm{~cm}$, has been shown to adversely affect mortality in multiple trials [1-4]

Theresa et al., showed in his study, that there may be a trend toward significance for the adverse effect of extrathyroidal extension (T3) on mortality $(p=0.07)[6]$.

He also showed that although greater tumor size (i.e., $>4 \mathrm{~cm}$ ) was found to be a predictor of multiple recurrences in patients with WDTC, it did not appear to predict for mortality in his study [6].

However in our study, tumor size in the thyroid gland showed that it had no relation with L.N. affection in early first recurrence with significant correlation ( $p$-value $<0.025$ ), and showed no significant correlation with operative bed recurrence ( $p$-value 0.448).

This is in agreement with the study carried by Orlov et al., on 246 patients followed for 5.8 years which found that age and tumor size were not helpful to predict recurrence; instead extra-thyroid invasion and positive L.N.s are correlated with recurrence indicating that surgical pathology findings are better prognostic indicators than TNM staging [16].

Veburg et al., showed in his study that was conducted on 935 patients followed for 30 years that increasing tumor size is associated with an exponentially increasing cumulative risk of local invasion, L.N. metastasis, and distant metastasis. He showed that aggressive biological behavior and tumor capsular extension were important associated factors [17].

Ito et al., also showed in his study that ten year recurrence rate for L.N. was $1.9 \%$ for tumors < than $2 \mathrm{~cm}$., $4.6 \%$ for tumors $2.1-4 \mathrm{~cm}$. and $8.1 \%$ for tumors more than $4 \mathrm{~cm}$. Ten years recurrence rate for operative bed was $0.3 \%$ for tumors < or $=$ to $2 \mathrm{~cm} ., 1.3 \%$ for tumors $2.1-4 \mathrm{~cm}$ and $1.9 \%$ for tumors more than $4 \mathrm{~cm}$ [18].

Although larger size of thyroid tumor when first removed may affect recurrence and convey poorer prognosis however in our study it showed 
that it had no relation with affection of L.N.s with the recurrent tumor (in recurrence in less than 12 months), as lesions as small as $1 \mathrm{~cm}$. may have associated L.N. affection, while tumors as large as $8 \mathrm{~cm}$. may not have L.N. affection in first recurrence, indicating that other factors affecting biological behavior may be the cause of recurrence.

Zamen et al., also showed that highest cumulative risk for nodal and distant metastasis occurs in tumor $=$ or $>5 \mathrm{~cm}$ and may indicate an aggressive behavior of the tumor specially in those $2 \mathrm{~cm}$. or less [19].

From the thirty five patients with positive first nodal recurrence, nineteen patients had tumors 3 $\mathrm{cm}$ or less. (Between 1 and $3 \mathrm{~cm}$.) in the thyroid gland when first removed (54.28\%), and sixteen patients had tumors more than $3 \mathrm{~cm}$ (between 3 and $8 \mathrm{~cm})(45.71 \%)$.

In the 5 patients with no L.N. affection in first recurrence, size of thyroid lesions ranged between 5 and $8 \mathrm{~cm}$.

However no correlation was found between size of the thyroid tumor when first removed in surgery, and number of pathologically +ve nodes. $(r=157, p$-value 0.453$)$.

Although no significant correlation was found between size of thyroid tumor when first removed and number of recurrences, however patients with more than one recurrence had median tumor size $4 \mathrm{~cm}$, while patients with one recurrence had median tumor size $3 \mathrm{~cm}$.

\section{Conclusions:}

Although size of primary thyroid tumor when first removed is an important factor that may affect recurrence and hence patients outcome, however it didn't show that it may affect L.N.s metastasis in subsequent recurrence. Size of primary thyroid tumor is not a predictor for L.N. metastasis in subsequent first early recurrence. (Less than 12 months).

The authors declare no conflict of interest.

\section{References}

1- S.L. CUSHING, C.E. PALME, N. AUDET, S. ESKI, P.G. WALFISH and J.L. FREEMAN: "Prognostic factors in well-differentiated thyroid carcinoma," Laryngoscope, Vol. 114, No. 12, pp. 2110-5, 2004.

2- A.R. SHAHA: "Implications of prognostic factors and risk groups in the management of differentiated thyroid cancer," Laryngoscope, Vol. 114, No. 3, pp. 393-402, 2004.
3- A. JUKKOLA, R. BLOIGU, T. EBELING, P. SALMELA and G. BLANCO: "Prognostic factors in differentiated thyroid carcinomas and their implications for current staging classifications," Endocrine-Related Cancer, Vol. 11, No. 3, pp. 571-9, 2004.

4- S.ORTIZ, J.M. RODRÍGUEZ, P. PARRILLA, et al.: "Recurrentpapillary thyroid cancer: Analysis of prognostic factors including the histological variant," European Journal of Surgery, Vol. 167, No. 6, pp. 406-12, 2001.

5- C.E. PALME, Z. WASEEM, S.N. RAZA, S. ESKI, P. WAL-FISH and J.L. FREEMAN: "Management and outcome of recurrent well-differentiated thyroid carcinoma," Archives of Otolaryngology-Head and Neck Surgery, Vol. 130, No. 7, pp. 819-24, 2004.

6- THERESA HOLLER, JENNA THERIAULT, RICHARD J. PAYNE, JONATHAN CLARK, SPIRO ESKI and JEREMY L. FREEMAN: "Prognostic factors in patients with multiple recurrences of Well-Differentiated Thyroid Carcinoma," Journal of Oncology, Volume 2009, Article ID 650340, 6 pages, doi: 10.1155/2009/650340.

7- M. TUBIANA, M. SCHLUMBERGER, P. ROUGIER, et al.: "Long-term results and prognostic factors in patients with differentiated thyroid carcinoma," Cancer, Vol. 55, No. 4, pp. 794-804, 1985.

8- C.E. PALME, Z. WASEEM, S.N. RAZA, S. ESKI, P. WAL-FISH and J.L. FREEMAN: "Management and outcome of recurrent well-differentiated thyroid carcinoma," Archives of Otolaryngology-Head and Neck Surgery, Vol. 130, No. 7, pp. 819-24, 2004.

9- SCHLUMBERGER M. and PACINI F.: Thyroid tumors. Paris, France: Editions Nucleón, 2006.

10- J.P. SHAH, T.R. LOREE, D. DHARKER, E.W. STRONG C. BEGG and V. vlamis: "Prognostic factors in differentiated carcinoma of the thyroid gland," The American Journal of Surgery, Vol. 164, No. 6, pp. 658-61, 1992.

11- W. EICHHORN, H. TABLER, R. LIPPOLD, M. LOCHMANN, M. SCHRECKENBERGER and P. BARTENSTEIN: "Prognostic factors determining long-term survival in well-differentiated thyroid cancer: An analysis of four hundred eighty-four patients undergoing therapy and aftercare at the same institution," Thyroid, Vol. 13, No. 10, pp. 949-58, 2003.

12- LONDERO S.C., KROGDAHL A., BASTHOLT L., OVERGAARD J., TROLLE W., PEDERSEN H.B., BENTZEN J., SCHYTTE S., CHRISTIANSEN P. and GODBALLE C.: Papillary thyroid microcarcinoma in Denmark 1996-2008: A national study of epidemiology and clinical significance. Thyroid, 23 (9): 1159-64. Doi: 10.1089/thy.2012.0595, 2013.

13-ARDITO G., REVELLI L., GIUSTOZZI E., SALVATORI M., FADDA G., ARDITO F., AVENIA N., FERRETTI A., RAMPIN L., CHONDROGIANNIS S., COLLETTI P.M. and RUBELLO D.: Aggressive papillary thyroid microcarcinoma: Prognostic factors and therapeutic strategy. Clin. Nucl. Med., 38 (1): 25-8. Doi: 10.1097/ RLU.0b013 e318279bc65, 2013.

14- H.S. WU, M.T. YOUNG, P.H. GITUARTE, et al.: "Death from thyroid cancer of follicular cell origin," Journal of the American College of Surgeons, Vol. 191, No. 6, pp. 600-6, 2000. 
15- W.M. McCONAHEY, I.D. HAY, L.B. WOOLNER, J.A VANHEERDEN and W.F. TAYLOR: "Papillary thyroid cancer treated at the mayo clinic, 1946 through 1970: Initial manifestations, pathologic findings, therapy, and outcome," Mayo Clinic Proceedings, Vol. 61, No. 12, pp. 978-96, 1986.

16- ORLOV S., ORLOV D., SHAYTZAG M., et al.: Influence of age and primary tumor size on the risk for residual/ recurrent well differentiated thyroid carcinoma. (Head neck), 31: 782-8, 2009.

17- VERBURG F.A., MADER U., LUSTER M., REINERS C., et al.: Primary tumor diameter as a risk factor for advanced disease features of differentiated thyroid carci- noma. Clin. Endocrinol. (Oxford). Aug., 71 (2): 291-7. doi:10.1111/j. 1365-2265.03482.x.Epub 2008 Dec. 3, 2009.

18-ITO Y., KUDO T., KIHARA M., TAKAMURA Y., KOBAYASHI K., MIYA A., MIYAUCHI A., et al.: Prognosis for low risk papillary thyroid carcinoma patients: It's relationship with the size of the primary tumors. Endocr. J., 59 (2): 119-25 EPub. 2011 Nov. 9, 2012.

19- ZAMAN M.U., FATIMA N., SAJJAD Z., AKHTAR J., ISLAM N., MASOOD A., et al.: Threshold primary tumour sizes for nodal and distant metastasis in papillary and follicular thyroid cancer. Asian Pac. J. Cancer Prev., 13 (6): 2473-6, 2012.

\title{
حجم الورم فى الغدة الدرقية ليس عامل لتوقع تآثير

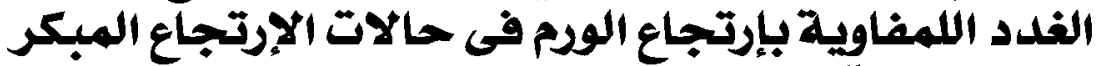

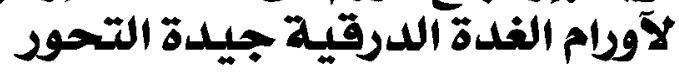

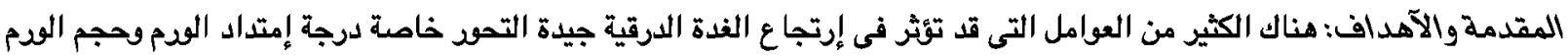

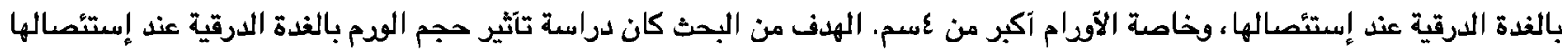

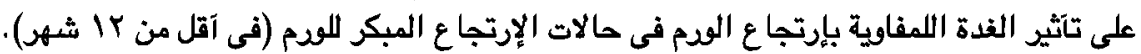 \\ النتائج:وجد آن حجم الودم في الغدة الدرقية عند إستئصالها ليس له علاقة بإرتداد الودم بالغدل اللمفاوية في حالة الإرتجاع المبكر للودم

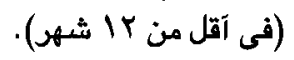

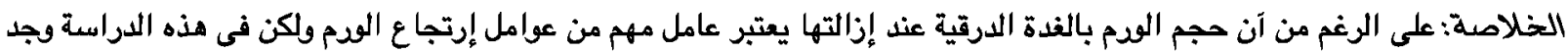

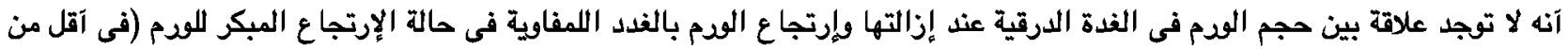

